\title{
The determination of metal content, microbial contamination and dissolution assessment of the ethanol extract of pasak bumi root
}

\section{Penetapan kadar logam, cemaran mikroba dan uji disolusi kapsul ekstrak etanol akar pasak bumi}

\author{
Laela Hayu Nurani ${ }^{* 1}$, Eka Kumalasari ${ }^{2}$, Zainab ${ }^{1}$, Achmad Mursyidi ${ }^{1}$, Sitarina \\ Widyarini $^{3}$, Abdul Rohman ${ }^{4}$ \\ ${ }^{1}$ Fakultas Farmasi Universitas Ahmad Dahlan \\ Jl. Prof. Dr. Soepomo, S.H., Janturan, Yogyakarta \\ ${ }^{2}$ Akademi Farmasi ISFI Banjarmasin \\ Jl. Flamboyan III No.7B Kayutangi, Banjarmasin, Kalimantan Selatan \\ ${ }^{3}$ Fakultas Kedokteran Hewan, Gadjah Mada Yogyakarta \\ Jl. Fauna No. 2 Karangmalang, Yogyakarta 55281 \\ ${ }^{4}$ Fakultas Farmasi, Univeritas Gadjah Mada Yogyakarta \\ Sekip Utara, Yogyakarta 55281
}

\begin{abstract}
ABSTRAK
Semua bagian pasak bumi terasa pahit oleh karena itu, untuk menutupi kekurangan bahan alam tersebut sediaan dibuat dalam bentuk kapsul. Bentuk sediaan kapsul harus memenuhi parameter kualitas yang baik, dengan demikian diharapkan dapat meningkatkan penggunaan potensi keanekaragaman hayati dan minat masyarakat dalam mengonsumsi obat dari bahan alam. Tujuan penelitian ini adalah mendapatkan produk kapsul ekstrak etanol akar pasak bumi yang berkualitas melalui uji nilai angka lempeng total dan cemaran kapang khamir, penetapan kandungan logam $\mathrm{Pb}, \mathrm{Hg}, \mathrm{Cd}$ serta kadar flavonoid yang terlepas pada uji disolusi kapsul ekstrak etanol akar pasak bumi. Hasil penelitian diperoleh nilai efisiensi disolusi $\left(\mathrm{ED}_{120}\right)$ kapsul ekstrak etanol akar pasak bumi sebesar $81,04 \pm 2,38 \%$. Uji kandungan logam berat di dalam kapsul ekstrak etanol akar pasak bumi ditemukan kadar $\mathrm{Pb}$ sebesar 4,132 ppm dan tidak terdeteksi kandungan $\mathrm{Cd}$ dan $\mathrm{Hg}$ di dalam kapsul. Hal ini menunjukkan bahwa kapsul memenuhi persyaratan yang ditetapkan oleh BPOM RI. Pengujian angka lempeng total (ALT) dan kapang khamir kapsul ekstrak etanol akar pasak bumi masing-masing memperoleh data sebesar $70 \times 10^{2} \mathrm{koloni} / \mathrm{g}$ dan $4 \mathrm{x}$ $10^{2}$ koloni/g. Hal ini juga menunjukkan bahwa kapsul memenuhi persyaratan oleh BPOM RI.
\end{abstract}

Kata kunci: akar pasak bumi, kapsul, disolusi, cemaran mikroba, logam berat

\section{ABSTRACT}

The Eurycoma longifolia is bitter therefore, to address this problem, it is prepared in a capsule form. The capsule dosage form must has the parameters of good quality, thus expected to increase the potential use of biodiversity and the interest of the community in consuming the medicine from the natural materials.

\footnotetext{
Penulis korespondesi:

Laela Hayu Nurani

Universitas Ahmad Dahlan

Jl. Prof. Dr. Soepomo, S.H., Janturan, Yogyakarta

Email: laelafarmasi@yahoo.com
} 
The purpose of this research is to get the capsule product of ethanol extract of the Eurycoma longifolia root of quality through the test of total plate value and yeast yeast contamination, the determination of the metal content of $\mathrm{Pb}, \mathrm{Hg}, \mathrm{Cd}$ and the level of flavonoids released in the capsule dissolution test of ethanol extract Eurycoma longifolia root. The result of this research shows that the dissolution efficiency $\left(\mathrm{DE}_{120}\right)$ capability of ethanol extract of Eurycoma longifolia root is $81,04 \pm 2,38 \%$. Test of heavy metal content in capsule of of ethanol extract of Eurycoma longifolia root found level of $\mathrm{Pb}$ equal to 4,132 ppm and not detected content of $\mathrm{Cd}$ and $\mathrm{Hg}$ in capsule. This indicates that the capsule meets the requirements set by BPOM RI. Tests for total plate numbers (ALT) and yeast capsule ethanol extract of the E. longifolia root were each obtained data of $70 \mathrm{x}$ $10^{2}$ colonies / $\mathrm{g}$ and $4 \times 10^{2}$ colonies / g. It also shows that the capsules meet the requirements by BPOM RI.

Keywords: Eurycoma longifolia Root, capsule, dissolution, microbial contamination, heavy metals

\section{PENDAHULUAN}

Akar pasak bumi (Eurycoma longifolia) mengandung senyawa flavonoid (Nurani et al., 2008), alkaloid (Bhat et al., 2010), $\beta$-carboline, canthine-6-one, quassinoids (laurycomalactone, eurycomalactone, longilactone, eurylactone, dan eurycomanone), turunan squalene, triterpen tirucallane, mucopolysaccharides, biphenylneolignans, dan eurypeptides. Berdasarkan studi farmakologi akar pasak bumi memiliki aktivitas sebagai antioksidan, antidiabetes, antikanker, dan afrodisiaka (Li et al., 2013). Akar pasak bumi (APB) juga digunakan sebagai antimalaria, antipiretik (Athimulam et al., 2006), antiinflamasi (Han et al., 2015), antihipertensi (Chen et al., 2015) dan imunostimulator (Tee et al., 2005).

Akar pasak bumi (APB) dianggap aman selama tidak digunakan dalam dosis tinggi. Berdasarkan hasil penelitian toksisitas sebelumnya, akar pasak bumi dianjurkan untuk diberikan kepada manusia di dosis 200-400 mg (Rehman et al., 2016).

Semua bagian pasak bumi terasa pahit karena mengandung beberapa macam kuasinoid, saponin, sitosterol dan stigmasterol (Bedir et al., 2003; Novianti, 2015). Oleh karena itu, untuk menutupi kekurangan bahan alam tersebut sediaan dibuat dalam bentuk kapsul. Kapsul merupakan sediaan oral yang sederhana dengan biaya produksi lebih sedikit dibandingkan dengan tablet dan praktis digunakan dalam rangka meningkatkan kepatuhan pasien (Tunsirikongkon et al., 2013).

Kapsul yang mengandung ekstrak kental dengan kadar air cukup tinggi memerlukan perlakuan khusus untuk menghasilkan kapsul yang baik. Oleh karena itu perlu adanya formulasi dengan eksipien yang mampu menjaga higroskopisitas sediaan kapsul (BPOM, 2012). Formulasi serbuk sering membutuhkan penambahan zat pengisi, lubrikan, dan glidan pada bahan aktif untuk mempermudah proses pengisian kapsul (Roselyndiar, 2012 ). Formulasi juga perlu dilakukan untuk memperoleh produk yang memenuhi persyaratan kualitas (Widyastuti, 2013). Menurut BPOM (2014) dan Farmakope indonesia edisi IV sediaan kapsul harus memenuhi syarat keseragaman bobot, waktu hancur, uji disolusi, dan memiliki angka cemaran kapang dan khamir dalam jumlah terbatas serta mengandung logam berat dalam kadar yang terbatas.

Berdasarkan uraian-uraian tersebut perlu dilakukan penelitian formulasi kapsul ekstrak etanol pasak bumi yang memenuhi persyaratan kualitas. Penelitian ini bertujuan untuk mengetahui (1) nilai angka lempeng total dan cemaran kapang khamir (2) nilai kandungan logam $\mathrm{Pb}, \mathrm{Hg}, \mathrm{Cd}$ serta (3) kadar flavonoid yang terlepas pada uji disolusi kapsul ekstrak etanol akar pasak bumi.

\section{METODE PENELITIAN}

Penelitian ini menggunakan desain penelitian eksperimental. Penelitian ini dilaksanakan di laboratorium Farmasi Universitas Ahmad Dahlan Daerah Istimewa Yogyakarta dan Laboratorium MIPA UGM Yogyakarta. 


\section{Alat dan Bahan}

Peralatan yang digunakan dalam penelitian ini adalah alat gelas (Iwaki, Japan) neraca analitik (Ohaus, USA), rotary evaporator (Heidolph, Germany), water bath (Mammert, Germany), halogen moisturizer analyzer (Mettler Toledo, Swiss), oven (Binder, Germany), spektrofotometer (Shimadzu, Japan).

Bahan yang digunakan dalam penelitian ini adalah akar pasak bumi yang diperoleh dari Kalimantan selatan, etanol $70 \%$, vivapur 101, talk, Mg Stearat, aerosil, amilum maydis, dan cangkang kapsul gelatin diperoleh dari Bratachem Yogyakarta.

\section{Jalannya Penelitian}

\section{Determinasi akar pasak bumi}

Determinasi akar pasak bumi dilakukan di Laboratorium Biologi, Universitas Ahmad Dahlan.

\section{Ekstraksi akar pasak bumi}

Akar pasak bumi diperoleh dari Banjarmasin Kalimantan Selatan kemudian dibuat serbuk dan dikeringkan di Laboratorium Teknologi Sediaan Farmasi UAD. Lakukan pemeriksaan standardisasi simplisia. Selanjutnya Pembuatan ekstrak dilakukan dengan merendam 2,5 kg serbuk ke dalam etanol (70\%) sebanyak 8 liter distirer selama 3 jam kemudian didiamkan selama 24 jam, kemudian maserat diperas dengan kain flannel dan proses maserasi diulang 2 kali. Filtrat diuapkan dengan rotary evaporator dengan suhu $60^{\circ} \mathrm{C}$ sampai diperoleh ekstrak kental. Selanjutnya dilakukan uji standarisasi ekstrak meliputi penetapan kadar air, penetapan kadar abu, pemeriksaan organoleptis (DepKes RI, 2012).

\section{Penetapan kadar air}

Ekstrak ditimbang 1,5 gram diletakkan pada lempeng yang terbuat dari alumunium, dimasukan kedalam alat halogen moisturizer analyzer, sehingga kadar air dapat diketahui (Depkes RI, 2008)

\section{Penetapan kadar Abu}

Sebanyak 2 sampai 3 g ekstrak ditimbang seksama dan dimasukkan ke dalam krus silikat yang telah dipijar dan ditara, lalu dipijarkan perlahan-lahan hingga arang habis dan bobot tetap, didinginkan dan ditimbang. Kadar abu total dihitung terhadap berat bahan uji, dan dinyatakan dalam \% b/b (Depkes RI, 2008)

\section{Pemeriksaan organoleptis}

Parameter organoleptik ekstrak ditetapkan menggunakan panca indera dengan mendiskripsikan bentuk, warna, bau dan rasa (Stahl, 2014)

Penetapan Kadar logam

Penetapan kadar logam didalam ekstrak dilakukan secara destruksi basah dengan asam nitrat dan hidrogen peroksida, kemudian kadar logam $\mathrm{Pb}, \mathrm{Hg}, \mathrm{Cd}$ ditentukan dengan spektrofotometri serapan atom (Depkes RI, 2014)

\section{Penetapan Angka Lempeng Total (ALT)}

Penentuan angka lempeng total dilakukan dengan mengambil sebanyak $1 \mathrm{ml}$ ekstrak yang telah diencerkan $10^{-4}$, ditanam dalam medium NA, lalu diinkubasi pada suhu $37^{\circ} \mathrm{C}$ selama 24 jam. Kemudian diamati dan dihitung jumlah koloni yang tumbuh dan dikalikan dengan faktor pengenceran. 
Penetuan angka kapang khamir dilakukan dengan mengambil sebanyak $1 \mathrm{ml}$ ekstrak yang telah diencerkan $10^{-4}$, ditanam dalam medium PDA, lalu diinkubasi pada suhu $25^{\circ} \mathrm{C}$ selama 3 hari. Kemudian diamati dan dihitung jumlah koloni yang tumbuh dan dikalikan dengan faktor pengenceran (Depkes RI, 2000)

\section{Pembuatan kapsul dan standarisasinya}

Kapsul pasak bumi dibuat dengan formula: Ekstrak kental sebanyak 84 gram dan vivapur 101 sebanyak 84 gram, amilum jagung, aerosil 3\%, talk 2\% dan Mg stearat 1\%. Uji standarisasi produk meliputi uji keseragaman bobot, uji waktu hancur, dan uji disolusi.

\section{Uji keseragaman bobot}

Dua puluh kapsul ditimbang. Timbang lagi kapsul satu persatu. Isi kapsul dikeluarkan, ditimbang seluruh bagian cangkang kapsul, bobot isi kapsul dan bobot rata-rata tiap isi kapsul dihitung. Perbedaan dalam persen bobot isi tiap kapsul terhadap bobot rata-rata tiap isi kapsul tidak boleh lebih dari $\pm 7,5 \%$ dan untuk setiap 2 kapsul tidak boleh dari $\pm 15 \%$ (DepKes, 2014).

\section{Uji waktu hancur}

Enam kapsul di masukkan ke dalam keranjang, keranjang diturun-naikkan secara teratur 30 kali tiap menit. Digunakan media air bersuhu $37 \pm 2^{\circ} \mathrm{C}$. Dilakukan pengamatan terhadap kapsul, semua kapsul harus hancur, kecuali bagian dari cangkang kapsul. Kecuali dinyatakan lain waktu yang diperlukan untuk menghancurkan keenam kapsul tidak boleh lebih dari 15 menit (DepKes, 2014).

\section{Uji disolusi}

Uji disolusi dilakukan dengan menggunakan metode spektrofotometeri visibel.

\section{Penyiapan larutan pereaksi}

Pereaksi yang digunakan adalah larutan $\mathrm{AlCl}_{3} \cdot 6 \mathrm{H}_{2} \mathrm{O} 10 \%$ dan larutan $\mathrm{CH}_{3} \mathrm{COONa} 1 \mathrm{M}$. Larutan $\mathrm{AlCl}_{3} \cdot 6 \mathrm{H}_{2} \mathrm{O} 10 \%$ dibuat dengan cara melarutkan $10 \mathrm{~g} \mathrm{AlCl}_{3} \cdot 6 \mathrm{H}_{2} \mathrm{O}$ dalam aquades hingga $100 \mathrm{~mL}$. Larutan $\mathrm{CH}_{3} \mathrm{COONa} 1 \mathrm{M}$ dibuat dengan cara melarutkan $9,8 \mathrm{~g} \mathrm{CH}_{3} \mathrm{COONa}$ dalam aquades hingga $100 \mathrm{~mL}$ (Yulistika, 2014).

\section{Penyiapan larutan standar kuersetin}

Sebanyak 10,0 mg standar kuersetin ditimbang seksama lalu dilarutkan dalam etanol $96 \%$ p.a. sampai 50,0 mL. Dari larutan ini kemudian dibuat seri larutan $8 \mu \mathrm{g} / \mathrm{mL}, 10 \mu \mathrm{g} / \mathrm{mL}, 12 \mu \mathrm{g} / \mathrm{mL}$, $14 \mu \mathrm{g} / \mathrm{mL}, 16 \mu \mathrm{g} / \mathrm{mL}, 18 \mu \mathrm{g} / \mathrm{mL}$ (Yulistika, 2014).

\section{Penetapan operating time larutan kuersetin}

Dibuat larutan dengan konsentrasi $10 \mu \mathrm{g} / \mathrm{mL}$, larutan sebanyak 2,0 mL kemudian ditambahkan $100 \mu \mathrm{L} \quad \mathrm{AlCl}_{3} \cdot 6 \mathrm{H}_{2} \mathrm{O} \quad 10 \%$ dan $100 \mu \mathrm{L} \mathrm{CH}_{3} \mathrm{COONa} 1 \mathrm{M}$ kemudian ditambahkan aquades hingga volume 5,0 mL, selanjutnya absorbansi diamati dari menit ke-0 hingga menit ke60. Dari data yang diperoleh kemudian ditetapkan operating time (Yulistika, 2014).

\section{Penetapan panjang gelombang absorbansi maksimum larutan kuersetin}

Diambil larutan standar kuersetin $10 \mu \mathrm{g} / \mathrm{mL}$ sebanyak 2,0 mL, kemudian ditambah $100 \mu \mathrm{L}$ $\mathrm{AlCl}_{3} .6 \mathrm{H}_{2} \mathrm{O} 10 \%$ dan $100 \mu \mathrm{L} \mathrm{CH}_{3} \mathrm{COONa} 1 \mathrm{M}$ kemudian ditambahkan aquades hingga volume 5,0 $\mathrm{mL}$ kemudian diperiksa pada panjang gelombang antara 300-600 nm (Yulistika, 2014).

\section{Pembuatan kurva baku}

Diambil 2,0 mL dari masing-masing seri larutan, kemudian masing-masing seri larutan ditambah $100 \mu \mathrm{L} \mathrm{AlCl}_{3} \cdot 6 \mathrm{H}_{2} \mathrm{O} 10 \%$ dan $100 \mu \mathrm{L} \mathrm{CH}_{3} \mathrm{COONa} 1 \mathrm{M}$ kemudian ditambahkan aquades hingga volume 5,0 mL didiamkan sampai operating time pada suhu kamar. Absorbansi diukur pada panjang gelombang maksimumnya, kemudian dibuat kurva hubungan antara konsentrasi kuersetin $(\mu \mathrm{g} / \mathrm{mL})$ (sumbu x) dengan absorbansi (sumbu y) (Yulistika, 2014).

\section{Penetapan Kadar Flavonoid Total (\% Ekivalen Kuersetin)}

Sebanyak 2 buah kapsul ekstrak etanol APB dengan bobot masing-masing 300,0 mg, dilarutkan dengan etanol $96 \%$ p.a. hingga $10,0 \mathrm{~mL}$. Dari larutan tersebut diambil 2,0 mL lalu 
diencerkan dengan etanol $96 \%$ p.a. hingga $10,0 \mathrm{~mL}$ lalu dari larutan tersebut diambil 2,0 $\mathrm{mL}$ lalu ditambahkan dengan $100 \mu \mathrm{L} \quad \mathrm{AlCl}_{3} \cdot 6 \mathrm{H}_{2} \mathrm{O} \quad 10 \%$ dan $100 \mu \mathrm{L} \mathrm{CH} \mathrm{CH}_{3} \mathrm{COONa} 1 \mathrm{M}$. Campuran ditambahkan aquades hingga volume $5,0 \mathrm{~mL}$. Setelah itu ditunggu pada waktu operasi maksimal dan diukur absorbansinya pada panjang gelombang maksimum. Kadar Falavonoid total dinyatakan sebagai \% ekivalen kuersetin (Yulistika, 2014).

\section{Uji disolusi}

Kapsul yang sudah ditimbang bobotnya dimasukkan ke dalam medium disolusi $500 \mathrm{~mL}$ dapar fosfat $\mathrm{pH} 7,4$ suhu $37^{\circ} \mathrm{C}$. Keranjang diputar dengan kecepatan $100 \mathrm{rpm}$. Sampel diambil dari medium pada waktu 5, 10, 20, 30, 40, 50, 60, 70, 80, 90, 100, 110, dan 120 menit sebanyak 5,0 mL. Sebanyak 5,0 mL medium dimasukkan dalam wadah media disolusi untuk mengganti volume sampel. Sampel diukur kadarnya menggunakan spektrofotometer visibel (DepKes RI, 2014).

\section{HASIL DAN PEMBAHASAN}

Akar Pasak Bumi (APB) yang akan digunakan dideterminasi di Laboratorium Biologi Universitas Ahmad Dahlan, Daerah Istimewa Yogyakarta, Indonesia. Pembuatan ekstrak etanol APB dilakukan di laboratorium Fitokimia Fakultas Farmasi Universitas Ahmad Dahlan, Daerah Istimewa Yogyakarta, Indonesia.

Proses maserasi diawali dengan merendam 2,5 kg serbuk APB dengan 8 liter etanol 70\% disertai pengadukan menggunakan electric stirrer dengan kecepatan $300 \mathrm{rpm}$ selama 3 jam kemudian didiamkan hingga 24 jam. Setelah 24 jam, maserat disaring dan serbuk diremaserasi sebanyak 2 kali, maserat kemudian dikumpulkan. Maserat yang diperoleh kemudian disaring menggunakan corong buchner kemudian dipekatkan menggunakan vaccum rotary evaporator pada suhu $50^{\circ} \mathrm{C}$. Penguapan dilanjutkan diatas water bath pada suhu $50^{\circ} \mathrm{C}$ hingga diperoleh ekstrak kental. Rendemen ekstrak etanol APB yang diperoleh sebesar 3,81\%.

Hasil penetapan kadar air ekstrak etanol APB dengan halogen moisturizer analyzer diperoleh kadar 7,09 $\pm 0,032 \%$. Hal ini menunjukkan ekstrak etanol APB memenuhi syarat yang ditetapkan oleh BPOM (2012) bahwa syarat umum kadar air yang diperbolehkan didalam bahan adalah $10 \%$ b/b. Secara organoleptis ekstrak etanol APB yang diperoleh berwarna coklat gelap, kental, berminyak, rasa pahit, dan mempunyai bau yang khas. Pemeriksaan organoleptis bertujuan memberikan pengenalan awal ekstrak secara objektif berupa bentuk, warna, bau, dan rasa.

Ekstrak etanol APB juga dilakukan pengukuran kadar abu. Pengukuran kadar abu ekstrak etanol APB yang diperoleh sebesar 2,32 $\pm 0,059 \%$. Parameter kadar abu ini terkait dengan kemurnian dan kontaminasi suatu bahan. Semakin sedikit kadar abu terkandung semakin menunjukkan sedikit mineral (anorganik) dalam bahan tersebut (DepKes, 2000). Hasil penelitian standarisasi non spesifik terlihat pada Tabel I. Ekstrak tersebut kemudian dimasukkan dalam cangkang kapsul dan dilakukan standarisasi kapsul yang tersaji pada Tabel II.

Bahan utama dalam penelitian ini yakni ekstrak etanol APB yang secara organoleptis berupa ekstrak kental. Ekstrak kental atau cair jika dimasukkan ke dalam kapsul maka ekstrak tersebut diubah terlebih dahulu ke dalam bentuk kering, sehingga diperlukan bahan pengering dan tambahan/eksipien lain (Djatmiko, 2009). Ekstrak etanol APB juga memiliki rasa yang pahit karena mengandung senyawa kuasinoid (Teh et al., 2011). Hal ini merupakan salah satu faktor yang mendorong untuk dibuat dalam bentuk sediaan kapsul.

Formulasi kapsul ekstrak etanol APB dalam penelitian ini mengadopsi penelitian yang dilakukan oleh Roselindyar (2012), yang memperoleh formula kapsul kombinasi ekstrak herba seledri (Apium graveolens L.) dan daun tempuyung (Sonchus arvensis L.) yang memenuhi persyaratan Farmakope Indonesia edisi IV, yang terdiri dari campuran vivapur 101, aerosil, amilum jagung, Mg stearat, dan talk sebagai bahan tambahan.

Kapsul yang telah diformulasi selanjutnya dilakukan uji keragaman bobot dan uji waktu hancur kapsul. Penimbangan 20 kapsul ekstrak etanol APB menunjukkan tidak ada yang menyimpang lebih dari persyaratan. Simpangan baku relatif dari 20 bobot kapsul sebesar 0,007 . Uji 
waktu hancur terhadap 6 kapsul ekstrak etanol APB menunjukkan waktu hancur rata-rata 1menit 35 detik. Hasil uji waktu hancur menunjukkan bahwa kapsul memenuhi syarat uji waktu hancur sesuai Farmakope Indonesia edisi IV, yakni waktu hancur kurang dari 15 menit.

Tabel I. Standarisasi non spesifik ekstrak etanol akar pasak bumi (Eurycoma longifolia, Jack)

\begin{tabular}{|c|c|c|c|}
\hline $\begin{array}{c}\text { Standarisasi } \\
\text { ekstrak }\end{array}$ & Hasil & SD & $\mathrm{CV}$ \\
\hline Kadar air & $7,09 \%$ & 0,032 & 0,005 \\
\hline Kadar abu & $2,32 \%$ & 0,059 & 0,025 \\
\hline \multicolumn{4}{|l|}{ Organoleptis: } \\
\hline Warna & coklat gelap & & \\
\hline Rasa & Pahit & & \\
\hline Bau & Khas & & \\
\hline Rekstur & berminyak & & \\
\hline Rendemen & $3,81 \%$ & & \\
\hline
\end{tabular}

Tabel II. Standarisasi kapsul ekstrak etanol akar pasak bumi

\begin{tabular}{lccc}
\hline Standarisasi kapsul & Hasil & SD & CV \\
\hline keseragaman bobot & $0,353 \mathrm{~g}$ & 0,002 & 0,007 \\
waktu hancur & I menit 35 detik & 0,016 & 0,017 \\
\hline \multicolumn{1}{c}{$=3$} & & &
\end{tabular}

\section{Kandungan logam berat kapsul ekstrak etanol akar pasak bumi}

Produk herbal APB dapat terkontaminasi racun seperti logam berat yang dapat menyebabkan sitotoksik. $\mathrm{Cd}$ dan $\mathrm{Pb}$ merupakan racun bagi manusia bahkan dalam jumlah sedikit. Logam berat ini dapat menyebabkan berkurangnya perkembangan kognitif. Cd dapat mempengaruhi fungsi ginjal, menyebabkan kerusakan tulang dan defisiensi reproduksi. Karena toksisitasnya sehingga logam ini tidak dibutuhkan oleh tubuh. Logam berat diperbolehkan ada didalam produk dengan batasan nilai yang ditetapkan (Razak and Kofie, 2011).

Penetapan kandungan logam berat dilakukan dilaboratorium Kimia Analitik, Fakultas MIPA Universitas Gadjah Mada, Daerah Istimewa Yogyakarta, Indonesia. Hasil uji kandungan logam berat di dalam kapsul ekstrak etanol APB ditemukan kadar Pb sebesar 4,132 ppm dan tidak terdeteksi kandungan $\mathrm{Cd}$ dan $\mathrm{Hg}$ didalam kapsul. Hal ini menunjukkan bahwa kapsul memenuhi persyaratan yang ditetapkan oleh BPOM RI (2014) tentang persyaratan mutu obat tradisional, bahwa kapsul sebagai obat tradisional boleh mengandung logam berat dengan batasan nilai $\mathrm{Pb}$ kurang dari $10 \mathrm{mg} / \mathrm{kg}$ atau $\mathrm{mg} / \mathrm{L}$ atau ppm; Cd kurang dari $0,3 \mathrm{mg} / \mathrm{kg}$ atau $\mathrm{mg} / \mathrm{L}$ atau ppm; $\mathrm{Hg}$ kurang dari $0,5 \mathrm{mg} / \mathrm{kg}$ atau $\mathrm{mg} / \mathrm{L}$ atau $\mathrm{ppm}$.

\section{Angka lempeng total, cemaran bakteri dan kapang khamir kapsul ekstrak etanol akar pasak bumi}

Uji cemaran mikroba bertujuan untuk memberikan jaminan bahwa bahan tidak boleh mngandung bakteri patogen dan tidak mengandung mikroba non-patogen melebihi batas yang ditentukan karena berpengaruh pada stabilitas bahan dan berbahaya (toksik) bagi kesehatan 
(DepKes, 2000). Pengujian angka lempeng total (ALT) dan kapang khamir kapsul ekstrak etanol APB masing-masing memperoleh data sebesar $70 \times 10^{2} \mathrm{koloni} / \mathrm{g}$ dan $4 \times 10^{2} \mathrm{koloni} / \mathrm{g}$. Hal ini menunjukkan bahwa kapsul ekstrak etanol APB memenuhi persyaratan yang ditetapkan oleh BPOM RI (2014) tentang persyaratan mutu obat tradisional, bahwa kapsul sebagai obat tradisional tidak boleh tercemar batas cemaran mikroba kapsul dengan nilai ALT kurang dari $10^{4} \mathrm{koloni} / \mathrm{g}$ dan angka kapang khamir kurang dari $10^{3}$ koloni/g.

\section{Uji Disolusi}

\section{Penetapan kadar kuersetin ekstrak etanol akar pasak bumi}

Uji kuantitatif kadar flavonoid diukur dengan metode spektrofotometri visibel. Operating time standar kuersetin diperoleh pada menit ke-20 sampai menit ke-27. Panjang gelombang serapan maksimum pada penelitian ini adalah $430 \mathrm{~nm}$, yang ditetapkan mengunakan larutan standar kuersetin dengan konsentrasi $10 \mu \mathrm{g} / \mathrm{mL}$.

Pengukuran kurva baku dilakukan pada operating time dan panjang gelombang serapan maksimum. Berdasarkan perhitungan hasil uji dengan $\mathrm{x}$ adalah konsentrasi $(\mu \mathrm{g} / \mathrm{mL})$ dan y adalah absorbansi diperoleh persamaan regresi linier $\mathrm{y}=0,0302 \mathrm{x}-8,2666.10^{-3}$ dan $\mathrm{r}$ hitung sebesar 0,99024 . Menurut teori, untuk $\mathrm{n}=6$ dengan taraf kepercayaan 95\% maka harga $\mathrm{r}$ tabel adalah 0,7293. Oleh karena $r$ hitung dari persamaan regresi linier lebih besar dari $r$ tabel, maka dapat disimpulkan bahwa terdapat hubungan antara konsentrasi larutan standar kuersetin dengan absorbansi, dan persamaan regresi linier tersebut dapat digunakan untuk menghitung kadar flavonoid total.

Kadar flavonoid total ekstrak etanol APB ditetapkan menggunakan metode spektrofotometri visibel, didasarkan pada reaksi antara flavonoid dan pereaksi $\mathrm{AlCl}_{3}$ yang membentuk senyawa berwarna kuning, yang kemudian diukur dengan spektrofotometri visibel. Pengukuran dilakukan pada panjang gelombang maksimal. Kadar flavonoid total dinyatakan dengan \% ekivalen kuersetin. Hasil penetapan kadar flavonoid total ekstrak etanol APB tertera pada Tabel III.

Tabel III. Kadar flavonoid total ekstrak etanol akar pasak bumi (Eurycoma longifolia) (\% ekivalen kuersetin)

\begin{tabular}{ccccccc}
\hline $\begin{array}{c}\text { Berat } \\
(\mathbf{m g})\end{array}$ & Absorbansi & Kadar $(\mathbf{u g} / \mathbf{m L})$ & Kadar $(\%)$ & Rata-rata & SD & CV \\
\hline 1400 & 0,310 & 249,7793 & 0,0178 & & & \\
1400 & 0,300 & 241,5012 & 0,0172 & 0,0177 & 0,0004 & 2,2735 \\
1400 & 0,313 & 252,2627 & 0,0180 & & & \\
\hline
\end{tabular}

\section{Uji Disolusi}

Disolusi merupakan faktor penentu proses absorbsi obat didalam tubuh. Efektivitas suatu obat sangat ditentukan oleh kecepatan desintegrasi, deagregasi dan kecepatan disolusi (Hadisoewignyo and Fudholi, 2013). Uji disolusi pada sediaan kapsul bertujuan untuk mengukur dan mengetahui jumlah zat aktif yang terlarut dalam media cair yang diketahui volumenya pada suatu waktu tertentu sehingga dapat diketahui kecepatan terlepasnya zat aktif dari sediaan. Uji disolusi dilakukan pada media dapar $\mathrm{pH} 7,4$ sebanyak $500 \mathrm{~mL}$ selama 2 jam dengan pengambilan sampel sebanyak 13 kali yaitu pada menit ke- 5, 10, 20, 30, 40, 50, 60, 70, 80, 90, 100, 110, dan 120. Sampel diukur kadarnya menggunakan spektrofotometer visibel. Hasil percobaan memperoleh nilai efisiensi disolusi $\left(\mathrm{ED}_{120}\right)$ kapsul ekstrak etanol APB sebesar 68,03\%, yang berarti bahwa selama 120 menit sebanyak $81,04 \pm 2,383 \%$ kuersetin terlarut dalam media disolusi. Profil disolusi flavonoid pada kapsul ekstrak etanol APB dapat dilihat pada Gambar 1 dan Tabel IV. 


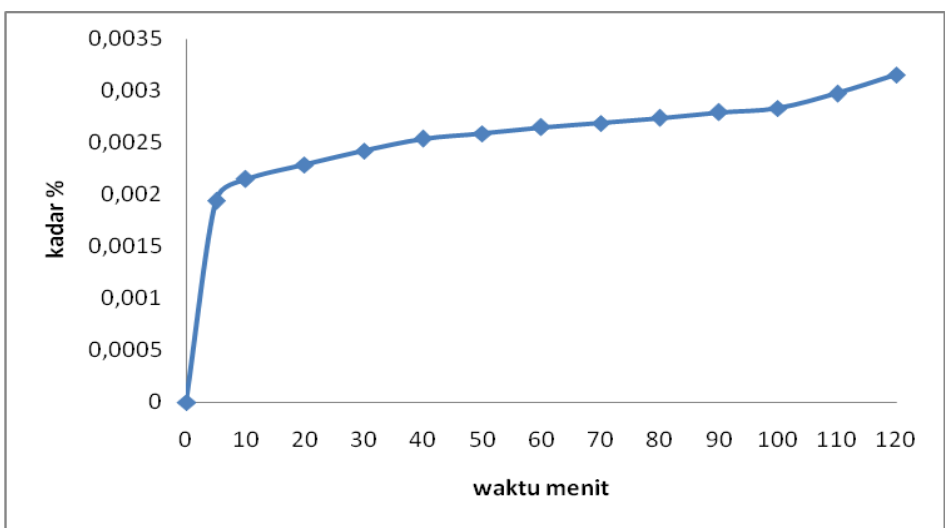

\section{Gambar 1. Profil pelepasan flavonoid kapsul ekstrak etanol akar pasak bumi (Eurycoma longifolia, Jack) di dalam media disolusi}

Tabel IV. Disolusi kapsul ekstrak etanol akar pasak bumi (Eurycoma longifolia) secara spektrofotometri visibel

\begin{tabular}{ccccccc}
\hline Replikasi & $\begin{array}{c}\text { kadar } \\
\text { hingga 120'}\end{array}$ & kadar total & $\begin{array}{c}\text { ED } \\
(\boldsymbol{\%})\end{array}$ & $\mathbf{X}$ & SD & CV \\
\hline 1 & 0,3051 & 0,3739 & 81,60 & & & \\
2 & 0,3044 & 0,3881 & 78,43 & 81,04 & 2,383 & 2,941 \\
3 & 0,3107 & 0,3739 & 83,10 & & & \\
\hline
\end{tabular}

Kecepatan disolusi dipengaruhi oleh beberapa faktor, antara lain: 1) Sifat fisika kimia obat, adanya perbedaan ukuran partikel dari zat khasiat obat akan mempengaruhi pelarutan. selain itu kelarutan obat dalam air juga mempengaruhi laju disolusi; 2) Faktor formulasi, berbagai macam bahan tambahan yang digunakan pada sediaan obat dapat mempengaruhi tegangan permukaan antara medium tempat obat melarut dengan zat khasiat obat, sehingga mempengaruhi kecepatan pelarutan zat khasiat obat; 3) Faktor alat dan kondisi lingkungan, adanya perbedaan alat yang digunakan dalam uji disolusi akan mempengaruhi kecepatan disolusi obat. Kecepatan pengadukan akan mempengaruhi kecepatan disolusi obat, semakin cepat pengadukan, semakin cepat pergerakan medium sehingga akan meningkatkan disolusi obat. Selain itu, suhu, viskositas, $\mathrm{pH}$, dan komposisi medium serta pengambilan sampel juga akan mempengaruhi kecepatan disolusi (Raini et al., 2010).

Absorpsi obat dalam tubuh bentuk kapsul tergantung dari pelepasan zat khasiat dari sediaan tersebut, kelarutan obat dalam kondisi fisiologis dan permeabilitas dalam melintasi saluran pencernaan. Sehingga, disolusi obat secara in vitro dapat memprediksi kinerja obat secara in vivo (Raini et al., 2010).

\section{KESIMPULAN}

Hasil standarisasi ekstrak etanol APB diperoleh kadar air 7,09 $\pm 0,032$, kadar abu 2,32 \pm 0,059. Hasil standarisasi kapsul ekstrak akar pasak bumi diperoleh kadar Pb sebesar 4,132 ppm dan tidak terdeteksi kandungan $\mathrm{Cd}$ dan $\mathrm{Hg}$. Pengujian angka lempeng total (ALT) dan kapang khamir kapsul ekstrak etanol APB masing-masing diperoleh $70 \times 10^{2} \mathrm{koloni} / \mathrm{g}$ dan $4 \times 10^{2} \mathrm{koloni} / \mathrm{g}$. Hasil efisiensi disolusi $\left(\mathrm{ED}_{120}\right)$ kapsul ekstrak etanol APB sebesar 81,04 $\pm 2,383 \%$. Hal ini menunjukkan bahwa kapsul memenuhi persyaratan yang ditetapkan oleh BPOM RI (2014) tentang persyaratan mutu obat tradisional. 


\section{UCAPAN TERIMAKASIH}

Penulis mengucapkan terima kasih kepada Lembaga Penelitian dan Pengembangan Universitas Ahmad Dahlan (LPP UAD) yang memberikan bantuan dana sehingga berjalannya penelitian ini.

\section{DAFTAR PUSTAKA}

Athimulam, A., Kumaresan, S., Foo, D. C. Y., Sarmidi1, M. R., and Aziz, R. A., 2006, Modelling and Optimization of Eurycoma longifolia Water Extract Production, Food and Bioproducts Processing, 84(C2): 139-149.

Bedir, E., Gazar, H., A., Ngwendson, J., N., and Khan, I., A., 2003, Eurycomaoside: A New Quassinoid-Type Glycoside from The Roots of Eurycoma longifolia, Chem Pharm. Bull, Vol 51, 1301-1303.

Bhat R. dan Karim, A.A., 2010, Tongkat Ali (Eurycoma longifolia Jack): A Review on Its Ethnobotany and Pharmacological Importance, Fitoterapia, 8: 669-679.

BPOM, 2012, Pedoman Teknologi Formulasi Sediaan Berbasis Ekstrak, 1:10-13, 15.

BPOM, 2014, Peraturan Kepala Badan Pengawasan Obat dan Makanan, Pedoman Pelaksanaan Uji Klinik Obat Herbal, Jakarta.

Chen, Y., Wai-Mei Phang, Alan K.-W.Mu, Choon-Keat Chan, Bin-Seng Low, Sreenivasan Sasidharan and Kit-Lam Chan, 2015, Deecreased Expression of Alpha-2-H Sglycoprotein in Thesera of Rat Streated with Extract Eurycoma Longifolia, Frontiers in Pharmacology, Volume 6, 1-6.

DepKes RI, 2000, Parameter standar umum ekstrak tumbuhan obat Edisi I , Direktorat Jenderal Pengawasan Obat dan Makanan, Direktorat Pengawas Obat Tradisional Jakarta

DepKes RI, 2008, Farmakope Herbal Indonesia, Edisi I, Departemen Kesehatan Republik Indonesia, Jakarta, 169.

DepKes RI, 2014, Farmakope Indonesia, Edisi V, Departemen Kesehatan Republik Indonesia, Jakarta, 59, 1436, 1439.

Djatmiko, M., 2009, Optimasi formulasi pembuatan simplisia, ekstrak dan granul herba seledri (Apium graveolans L.), Disertasi, Pascasarjana Studi Ilmu Farmasi, Universitas Gadjah Mada, Yogyakarta.

Hadisoewignyo, L. dan Fudholi, A., 2013, Sediaan Solida, Pustaka Pelajar, Yogyakarta.

Han, Young Min In Sook Kim, Shaheed Ur Rehman, Kevin Choe, and Hye Hyun Yoo, 2015, In Vitro Evaluation of the Effects of Eurycoma longifolia Extract on CYP-Mediated Drug Metabolism, Hindawi Publishing Corporation Evidence-Based Complementary and Alternative Medicine Volume 2015:1-6.

Li, Ching-Hao ,Jiunn-Wang Liao, Po-Lin Liao, Wei-Kuang Huang,,Ling-Shan Tse,Cheng-Hui Lin, Jaw-Jou Kang,and Yu-Wen Cheng, 2013, Evaluation of Acute 13-Week Subchronic Toxicity and Genotoxicity of the Powdered Root of Tongkat Ali (Eurycoma longifolia Jack), Hindawi Publishing Corporation, 1-11.

Novianti, S, 2015, Pemberian ekstrak etanol akar pasak bumi secara oral meningkatkan kadar hormon testosterone tikus wistar jantan tua, Tesis, Program Pasca SarjanaUniversitas Udayana.

Raini, M., Daroham M., dan Padji L., 2010, Uji Disolusi dan Penetapan Kadar Tablet Loratadin Inovator dan Generik Bermerek, Media Litbang Kesehatan, XX(2): 59-64.

Razak, M. F. A., Kofie, E.A., 2011, Toxicity Studies Of Eurycoma, Asian J Pharm Clin Res, 4(3): $1-6$.

Rehman, Shaheed Ur., Kevin Choe and Hye Hyun Yoo, 2016, Review on a Traditional Herbal Medicine, Eurycoma longifolia Jack (Tongkat Ali): Its Traditional Uses, Chemistry, Evidence-Based Pharmacology and Toxicology, Molecules Journal, 331(21): 1-31.

Roselyndiar, 2012, Formulasi Kapsul Kombinasi Ekstrak Herba Seledri (Apium graveolens L.) dan Daun Tempuyung (Sonchus arvensis L.), Skripsi, Fakultas MIPA, Universitas Indonesia. 
Stahl, E., 1985, Analisis Obat secara Kromatografi dan Mikroskopi, Edisi terjemahan (diterjemahkan oleh Kosasih Padmawinata, Iwang Soediro), ITB press, Bandung, 3-18.

Tee, T.T. dan Azimahtol, H.L.P., 2005, Induction of Apoptosis by Eurycoma longifolia jack extracts, Anticancer Research, 25: 2205-2213.

Teh, C.H., Vikneswaran, M., and Kit, L.C., 2011, Developing a Validated Liquid Chromatography-Mass Spectrometric Method For the Simultaneous Analysis of Five Bioactive Quassinoid Markers For the Standardization of Manufactured Batches of Eurycoma longifolia Jack Extract as Antimalarial Medicaments, Journal of Chromatography A, 1218: 1861-1877.

Tunsirikongkon, A., Pakorn, K., Supawadee, S., Arunporn, I., Narong, S. 2013 Formulation Development of Herbal Capsule Containing Oleoresin of zingiber officinale Extract. International Journal of Pharmacy and Pharmaceutical Sciences, 5(4): 439-445.

Widiyastuti, L, 2013, Formulasi Granul Kombinasi Ekstrak Terpurifikasi Herba Pegagan (Centella asiatica) dan Herba Sambiloto (Andrographis paniculata), Thesis, Fakultas Farmasi Universitas Gadjah Mada, Yogyakarta.

Yulistika, M, 2014, Optimasi Pelarut Etanol-Air Sebagai Penyari Flavonoid Total Dalam Pasak Bumi (Eurycoma longifolia, Jack) dengan Metode Simplex Lattice Design (SLD), Skripsi, Fakultas Farmasi, Universitas Ahmad Dahlan, Yogyakarta. 